\title{
Rotor Unbalance Estimation with Reduced Number of Sensors
}

\author{
Sami M. Ibn Shamsah * and Jyoti K. Sinha \\ School of Mechanical, Aerospace and Civil Engineering (MACE), The University of Manchester, \\ Manchester M13 9PL, UK; jyoti.sinha@manchester.ac.uk \\ * Correspondence: samimishal@gmail.com; Tel.: +44-78-6466-2157
}

Academic Editor: Steven Y. Liang

Received: 24 August 2016; Accepted: 19 October 2016; Published: 25 October 2016

\begin{abstract}
The most common cause of the excessive vibration in rotating machines is the rotor mass unbalance. If a machine vibration due to mass unbalance exceeds the alarm limits, then it may lead to machine failure. Therefore, rotating machines should be regularly checked to ensure that they are properly balanced. Currently, industries use the influence coefficient (IC) balancing technique for in situ machine balancing. The accepted practice is to use the vibration measurements in both vertical and horizontal directions at the machine-bearing pedestals together with the tachometer signal to estimate the machine rotor unbalance (both mass and phase angle). It is generally believed that the use of the machine vibration measurements in the vertical and horizontal directions represents better machine dynamics, and hence the estimated unbalance is likely to be more accurate. However, this paper applies the same concept of the IC method but with a reduced number of vibration sensors (one sensor per bearing pedestal at $45^{\circ}$ instead of two sensors at the vertical and horizontal directions). The use of one sensor per bearing pedestal at $45^{\circ}$ from both vertical and horizontal directions is likely to have responses from both directions. The reduction in the number of sensors by half will definitely save the instruments and their maintenance cost and reduce the computational effort in the signal processing significantly. The proposed concept is applied on a small-size laboratory rig with two balancing planes. The paper presents the unbalance estimations by using the measured vibration responses in both the vertical and horizontal directions simultaneously and using vibration responses measured at $45^{\circ}$.
\end{abstract}

Keywords: rotating machines; rotor unbalance; influence coefficient method; order tracking

\section{Introduction}

Rotating machines are considered the foundation of most industries such as oil and gas, mining and chemicals as they play a vital role in many activities. Therefore, it is of the utmost importance for any industry to ensure that their rotating machines are in good condition. Most of the rotating machines consist of several integrated components including the rotor, supporting structure, bearings, couplings, electric motor, etc. The dynamic conditions under which rotating machines operate make them vulnerable to a great variety of undesired aberrations that often result in different machine faults [1-3]. The machine rotor unbalance is observed to be one of the frequently occurring problems for any industrial rotating machine. Hence, regular in situ balancing is important to maintain the plant safety, reduce downtime and enhance production [3,4].

Several vibration-based rotor fault identification methods have been proposed in the literature [1-10]. The influence coefficient (IC) balancing method [11-15], the modal balancing [7] and other balancing methods [16-29] are the most utilized vibration-based unbalance identification methods. In order to apply the modal balancing method effectively, an accurate numerical model of the rotor and a highly skilled engineer with thorough knowledge of rotor dynamics are required [8]. 
The IC balancing approach does not involve any modeling of the rotor [3]. It only requires machine runs with trial weights [3]. Therefore, owing to its simplicity and high efficiency, the IC balancing technique has become the most commonly used balancing method in the industries.

Darlow [17], Fang et al. [18], Zhou et al. [19], Dyer et al. [20] and Parkinson [21] presented reviews of the literature on the IC balancing method. In 1964, Goodman [22] presented a least square approach to extend the method to multiple planes balancing using data from different machine speeds and measurement locations. Lund and Tonnesen [23] as well as Tessarzik et al. [24] have used this method for the rotor balancing. Yu [26] and Lee et al. [29] used the IC method to estimate the rotor unbalance at a constant rotor speed. Ibn Shamsah et al. [14,15] have used this method and highlighted that the use of more speeds simultaneously during the machine's transient operation (run-up or run-down) gives much better rotor unbalance estimates than at a single machine speed.

The accepted practice is to use the vibration measurements in both vertical and horizontal directions at the machine-bearing pedestals together with the tachometer signal to estimate the machine rotor unbalance (both mass and phase angle). It is generally believed that the use of the machine vibration measurements in the vertical and horizontal directions represents better machine dynamics, and hence the estimated unbalance is likely to be more accurate. However, this paper applies the same concept of the IC method but with a reduced number of vibration sensors (one sensor per bearing pedestal at $45^{\circ}$ instead of two sensors at the vertical and horizontal directions). The use of one sensor per bearing pedestal at $45^{\circ}$ from both the vertical and horizontal directions is likely to have responses from both directions. This reduction in the number of sensors by half will definitely save the instruments and their maintenance costs significantly. Furthermore, the signal processing time will be reduced significantly, and hence the balancing decision is made faster. The proposed concept is applied on a small-size laboratory rig with two balancing planes. The paper presents the unbalance estimations by using the measured vibration responses in both vertical and horizontal directions simultaneously as well as using vibration responses measured at $45^{\circ}$.

\section{Experimental Rig}

Figure 1 shows a photograph of the test rig used for the experiments. Basically, the rig is made up of three main components which are the rotor, bearings and foundation. The rotor of the rig is a mild steel circular cross-section shaft $(20 \mathrm{~mm} \times 1000 \mathrm{~mm})$ that is flexibly coupled to a $0.75 \mathrm{~kW}$, three-phase electric motor which has a variable speed range from 0 to $3000 \mathrm{rpm}$. The shaft has two identical discs at distances of 320 and $745 \mathrm{~mm}$ from the flexible coupling and they are supported by two ball bearings which are secured atop the flexible foundation. The discs, which have an outer diameter of $130 \mathrm{~mm}$ and a thickness of $20 \mathrm{~mm}$, contain staggered threaded holes (M5) in two different pitch diameters, which are 70 and $120 \mathrm{~mm}$. The angle between the two adjacent holes for each pitch diameter is $30^{\circ}$. The supporting structure of each bearing is comprised of a steel horizontal beam $(530 \mathrm{~mm} \times 25 \mathrm{~mm} \times 8 \mathrm{~mm})$ that is secured atop two rectangular steel blocks $(107 \mathrm{~mm} \times 25 \mathrm{~mm} \times 25 \mathrm{~mm}$ ). The supporting structure is mounted on a massive steel platform by means of four bolts. An anti-vibration (TICO) pad which has a thickness of $12 \mathrm{~mm}$ is attached to the bottom side of the steel platform for the purpose of mitigating noise and vibration. The bearing and disc closer to the coupling are denoted as B1 and D1 while the other bearing and disc are denoted as B2 and D2, respectively. 


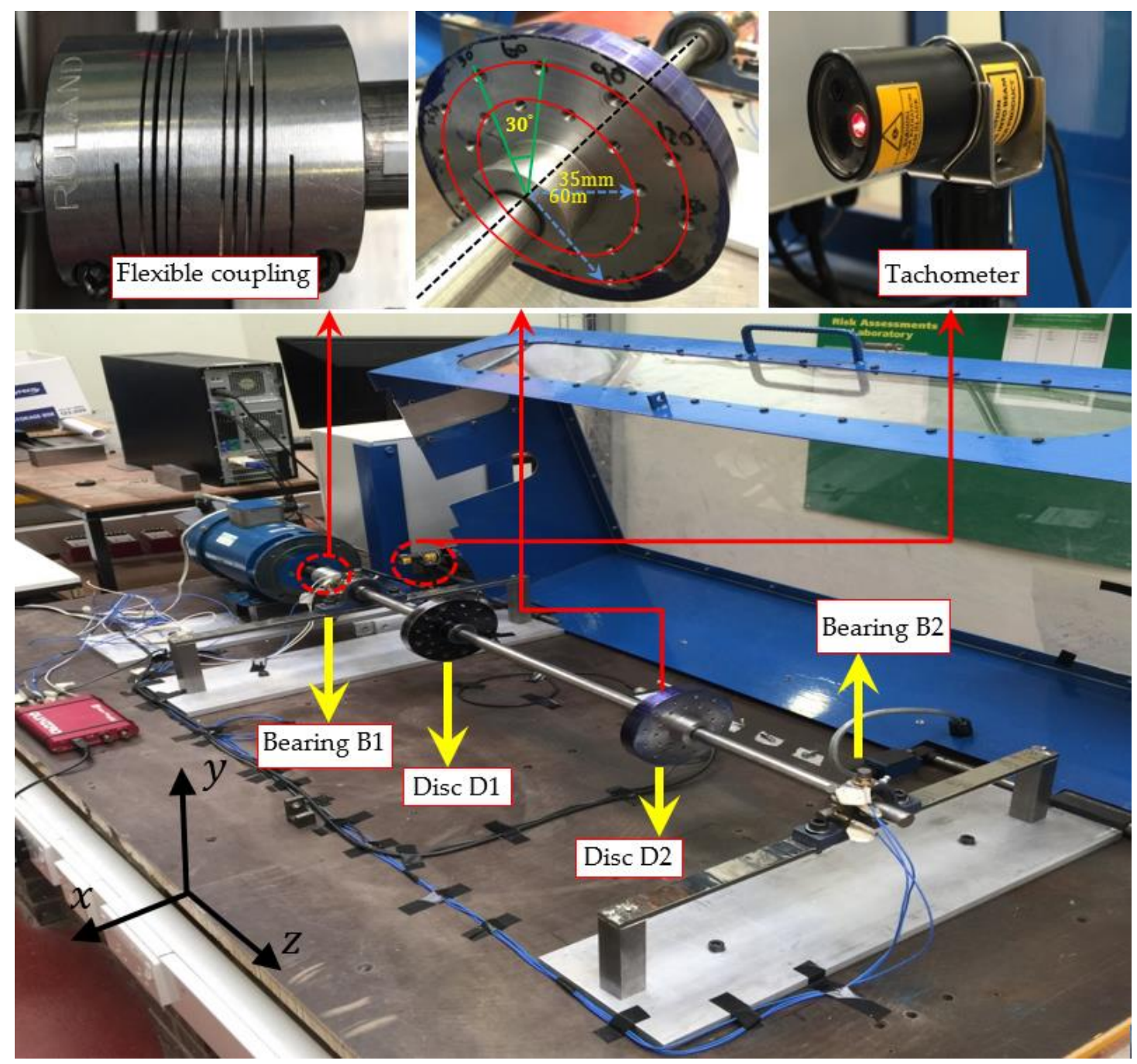

Figure 1. Mechanical layout of the experimental rig.

\section{Theory}

Assume that the displacement vectors in the vertical and horizontal directions at all bearing pedestals in a machine are $\mathbf{d}_{0}, \mathbf{d}_{1}, \mathbf{d}_{2}, \ldots, \mathbf{d}_{n}$, where the subscripts denote the first, second, third, $\ldots$, $(n+1)$-th machine run-ups, respectively. The displacement vectors for the different machine run-up speeds can be written as

$$
\begin{aligned}
\mathbf{d}_{0}= & {\left[\begin{array}{llllll}
\mathbf{d}_{0}\left(f_{1}\right) & \mathbf{d}_{0}\left(f_{2}\right) & \ldots & \mathbf{d}_{0}\left(f_{k}\right) & \ldots & \mathbf{d}_{0}\left(f_{N}\right)
\end{array}\right]^{T} } \\
\mathbf{d}_{1}= & {\left[\begin{array}{llllll}
\mathbf{d}_{1}\left(f_{1}\right) & \mathbf{d}_{1}\left(f_{2}\right) & \ldots & \mathbf{d}_{1}\left(f_{k}\right) & \ldots & \mathbf{d}_{1}\left(f_{N}\right)
\end{array}\right]^{T} } \\
\mathbf{d}_{2}= & {\left[\begin{array}{llllll}
\mathbf{d}_{2}\left(f_{1}\right) & \mathbf{d}_{2}\left(f_{2}\right) & \ldots & \mathbf{d}_{2}\left(f_{k}\right) & \ldots & \mathbf{d}_{2}\left(f_{N}\right)
\end{array}\right]^{T} } \\
& \vdots \\
\mathbf{d}_{n}= & {\left[\begin{array}{llllll}
\mathbf{d}_{n}\left(f_{1}\right) & \mathbf{d}_{n}\left(f_{2}\right) & \ldots & \mathbf{d}_{n}\left(f_{k}\right) & \ldots & \mathbf{d}_{n}\left(f_{N}\right)
\end{array}\right]^{T} }
\end{aligned}
$$

where $f_{1}, f_{2}, \ldots, f_{N}$ are the machine run-up speeds in $\mathrm{Hz}$, with $f_{N}$ as the maximum speed. Note that the displacement vector $\mathbf{d}_{0}$ is always for the machine's first run with residual rotor unbalance (i.e., 
without any trial masses on the balancing planes) that needs to be balanced. The rig has only two bearing pedestals. Hence, the displacement vectors at a single rotor speed $f_{k}$ can be written as

$$
\begin{aligned}
& \mathbf{d}_{1}\left(f_{k}\right)=\left[\begin{array}{lllll}
\mathrm{y}_{1,1}\left(f_{k}\right) & \mathrm{x}_{1,1}\left(f_{k}\right) & \mathrm{y}_{2,1}\left(f_{k}\right) & \mathrm{x}_{2,1}\left(f_{k}\right)
\end{array}\right]^{T} \\
& \mathbf{d}_{2}\left(f_{k}\right)=\left[\begin{array}{llll}
\mathrm{y}_{1,2}\left(f_{k}\right) & \mathrm{x}_{1,2}\left(f_{k}\right) & \mathrm{y}_{2,2}\left(f_{k}\right) & \mathrm{x}_{2,2}\left(f_{k}\right)
\end{array}\right]^{T} \\
& \mathbf{d}_{n}\left(f_{k}\right)=\left[\begin{array}{lllll}
\mathrm{y}_{1, n}\left(f_{k}\right) & \mathrm{x}_{1, n}\left(f_{k}\right) & \mathrm{y}_{2, n}\left(f_{k}\right) & \mathrm{x}_{2, n}\left(f_{k}\right)
\end{array}\right]^{T}
\end{aligned}
$$

where $\mathrm{y}_{1, n}$ and $\mathrm{x}_{1, n}$ are the displacements at the bearing $\mathrm{B} 1$ pedestal in the vertical and horizontal directions, respectively, for the $(n+1)$-th machine run. Similarly, $\mathrm{y}_{2, n}$ and $\mathrm{x}_{2, n}$ are the displacements at the bearing B2 pedestal in the vertical and horizontal directions, respectively, for the $(n+1)$-th machine run.

In the case of two balancing planes, the sensitivity matrix $\mathbf{S}$ is constructed using the measured vibration responses from the first three machine runs as written in Equation (3).

$$
\mathbf{S}=\left[\begin{array}{cc}
\frac{\mathbf{d}_{1}\left(f_{1}\right)-\mathbf{d}_{0}\left(f_{1}\right)}{e_{1,1}} & \frac{\mathbf{d}_{2}\left(f_{1}\right)-\mathbf{d}_{0}\left(f_{1}\right)}{e_{2,2}} \\
\frac{\mathbf{d}_{1}\left(f_{2}\right)-\mathbf{d}_{0}\left(f_{2}\right)}{e_{1,1}} & \frac{\mathbf{d}_{2}\left(f_{2}\right)-\mathbf{d}_{0}\left(f_{2}\right)}{e_{2,2}} \\
\vdots & \vdots \\
\frac{\mathbf{d}_{1}\left(f_{N}\right)-\mathbf{d}_{0}\left(f_{N}\right)}{e_{1,1}} & \frac{\mathbf{d}_{2}\left(f_{N}\right)-\mathbf{d}_{0}\left(f_{N}\right)}{e_{2,2}}
\end{array}\right]
$$

where $e_{1,1}$ is the added unbalance to the first balancing plane at the second machine run-up, and $e_{2,2}$ is the added unbalance to the second balancing plane at the third machine run-up.

The residual rotor mass unbalance $\mathbf{e}_{0}$ for each balancing plane can then be calculated using Equation (4).

$$
[\mathbf{S}]_{4 N \times 2}\left[\begin{array}{c}
e_{1,0} \\
e_{2,0}
\end{array}\right]_{2 \times 1}=\left[\mathbf{d}_{0}\right]_{4 N \times 1}
$$

The rotor mass unbalance $\mathbf{e}$ is a complex value and can further be written as

$$
\left[\begin{array}{cccc}
1 & j & 0 & 0 \\
0 & 0 & 1 & j
\end{array}\right]_{2 \times 4}\left[\begin{array}{c}
\operatorname{real}\left(e_{1,0}\right) \\
\operatorname{imag}\left(e_{1,0}\right) \\
\operatorname{real}\left(e_{2,0}\right) \\
\operatorname{mag}\left(e_{2,0}\right)
\end{array}\right]_{4 \times 1}=\mathbf{T e}_{0}
$$

where $\mathbf{T}$ is the transformation matrix. Substituting Equation (5) into Equation (4) gives

$$
[\mathbf{S}]_{4 N \times 2} \mathbf{T}_{2 \times 4}\left[\mathbf{e}_{\mathbf{0}}\right]_{4 \times 1}=\left[\mathbf{d}_{0}\right]_{4 N \times 1}
$$

Equation (6) can be rewritten as

$$
\left[\mathbf{S}_{T}\right]_{4 N \times 4}\left[\mathbf{e}_{\mathbf{0}}\right]_{4 \times 1}=\left[\mathbf{d}_{0}\right]_{4 N \times 1}
$$

where $\mathbf{S}_{T}=\mathbf{S T}$. The real and imaginary parts in Equation (7) are separated as

$$
\left[\begin{array}{cc}
\operatorname{real}\left(\mathbf{S}_{T}\right)_{4 N \times 4} \\
\operatorname{imag}\left(\mathbf{S}_{T}\right)_{4 N \times 4}
\end{array}\right]_{8 N \times 4}\left[\mathbf{e}_{\mathbf{0}}\right]_{4 \times 1}=\left[\begin{array}{c}
\operatorname{real}\left(\mathbf{d}_{0}\right)_{4 N \times 1} \\
\operatorname{imag}\left(\mathbf{d}_{0}\right)_{4 N \times 1}
\end{array}\right]_{8 N \times 1}
$$

Hence, 


$$
\left[\mathbf{S}_{s}\right]_{8 N \times 4}\left[\mathbf{e}_{0}\right]_{4 \times 1}=\left[\mathbf{d}_{0_{s}}\right]_{8 N \times 1}
$$

Rearranging Equation (9) gives

$$
\mathbf{e}_{\mathbf{0}}=\left[\mathbf{S}_{s}\right]^{+} \mathbf{d}_{0_{s}}
$$

where $\left[\mathbf{S}_{s}\right]^{+}$is the Moore-Penrose pseudo-inverse of $\left[\mathbf{S}_{s}\right]$, i.e., $\left[\mathbf{S}_{s}\right]^{+}=\left(\mathbf{S}_{s}^{T} \mathbf{S}_{s}\right)^{-1} \mathbf{S}_{s}^{T}$. Equation (4) can be further modified to calculate the added unbalances at the different planes simultaneously directly for each machine run,

$$
[\mathbf{S}]_{4 N \times 2}\left[\begin{array}{c}
e_{1, q} \\
e_{2, q}
\end{array}\right]_{2 \times 1}=\left[\mathbf{d}_{q}-\mathbf{d}_{0}\right]_{4 N \times 1}
$$

where the subscript $q$ in Equation (11) represents the $(q+1)$-th machine run. Thus, Equation (11) can be rewritten as

$$
\mathbf{e}_{\mathrm{q}}=\left[\mathbf{S}_{s}\right]^{+} \mathbf{d}_{\mathrm{q}, 0_{s}}
$$

In case of measurement at $45^{\circ}$ from the horizontal or vertical direction, the displacement vectors can be rewritten as

$$
\begin{aligned}
\mathbf{d}_{0}\left(f_{k}\right) & =\left[\begin{array}{ll}
\mathbf{r}_{1,0}\left(f_{k}\right) & \mathbf{r}_{2,0}\left(f_{k}\right)
\end{array}\right]^{T} \\
\mathbf{d}_{1}\left(f_{k}\right) & =\left[\begin{array}{ll}
\mathbf{r}_{1,1}\left(f_{k}\right) & \mathbf{r}_{2,1}\left(f_{k}\right)
\end{array}\right]^{T} \\
\mathbf{d}_{2}\left(f_{k}\right) & =\left[\begin{array}{cc}
\mathbf{r}_{1,2}\left(f_{k}\right) & \mathbf{r}_{2,2}\left(f_{k}\right)
\end{array}\right]^{T} \\
\vdots & \\
\mathbf{d}_{n}\left(f_{k}\right) & =\left[\begin{array}{cc}
\mathbf{r}_{1, \mathrm{n}}\left(f_{k}\right) & \mathbf{r}_{2, \mathrm{n}}\left(f_{k}\right)
\end{array}\right]^{T}
\end{aligned}
$$

where $\mathbf{r}_{1, n}\left(f_{k}\right)$ and $\mathbf{r}_{2, n}\left(f_{k}\right)$ are the radial displacements (i.e., $45^{\circ}$ from the vertical and horizontal directions) at the bearing B1 and B2 pedestals at the rotor speed $f_{k}$ for the $(n+1)$-th machine run.

\section{Experiments and Data Acquisition}

Modal tests [3] were conducted on the test rig at zero rpm. The rig was excited by an instrumented hammer (sensitivity of $1.1 \mathrm{mV} / \mathrm{g}$ ), and the machine vibration was measured by seven Integrated Circuit Piezo-electric (ICP) accelerometers (sensitivity of $100 \mathrm{mV} / \mathrm{g}$ ). Table 1 lists the experimentally identified natural frequencies and Figure 2 shows their corresponding mode shapes.

A total of 13 machine run-ups were carried out, and 10 unbalance estimation scenarios were used. For each of the 13 machine run-ups, the machine speed was increased linearly from $300 \mathrm{rpm}$ $(5 \mathrm{~Hz})$ to $3000 \mathrm{rpm}(50 \mathrm{~Hz})$ in a period of $135 \mathrm{~s}$. The different masses added to both balancing planes at a fixed radius of $6 \mathrm{~cm}$ for the different runs are listed in Table 2. The vibration responses were measured at both bearing housings/pedestals for each run. The measurements at each bearing were taken in three directions (vertical, horizontal and radial $45^{\circ}$ ) as shown in Figure 3. Since the rotor vibrations due to mass unbalance are synchronous to the rotational speed, the measured vibration responses of each machine run were order-tracked to get the $1 \times$ (one multiplied by rotating frequency) responses. The order-tracked $1 \times$ vibration displacement data in the speed range from 15 to $40 \mathrm{~Hz}$ (i.e., 900 to $2400 \mathrm{rpm}$ ) with an interval of $0.5 \mathrm{~Hz}(30 \mathrm{rpm})$ were used in the unbalance estimation. Few $1 \times$ order-tracked displacement responses are typically shown in Figure 4. The two critical speeds clearly appear in the responses shown in Figure 4 at around $22 \mathrm{~Hz}$ and $31 \mathrm{~Hz}$, so there is little shift in their values when compared to the natural frequencies at zero rpm that are listed in Table 1. 
Table 1. Experimentally identified natural frequencies of the test rig.

\begin{tabular}{cc}
\hline Mode & Frequency $\mathbf{( H z )}$ \\
\hline 1 & 24.41 \\
2 & 31.13 \\
3 & 53.1 \\
4 & 84.23 \\
\hline
\end{tabular}

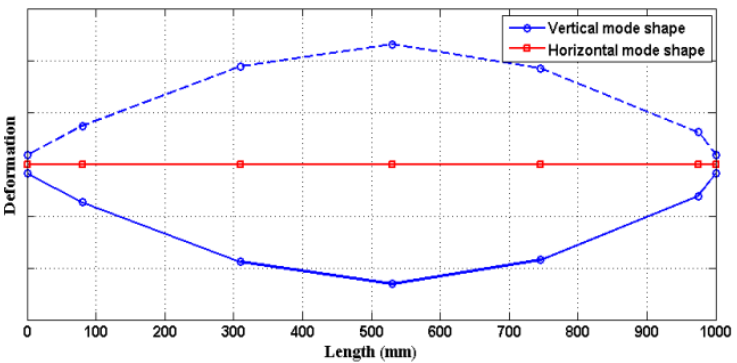

(a)

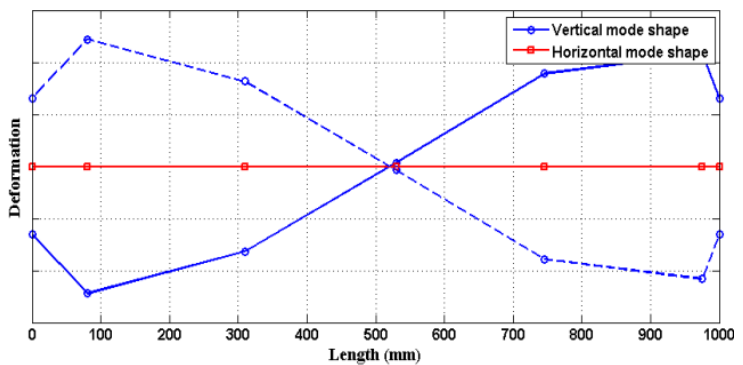

(c)

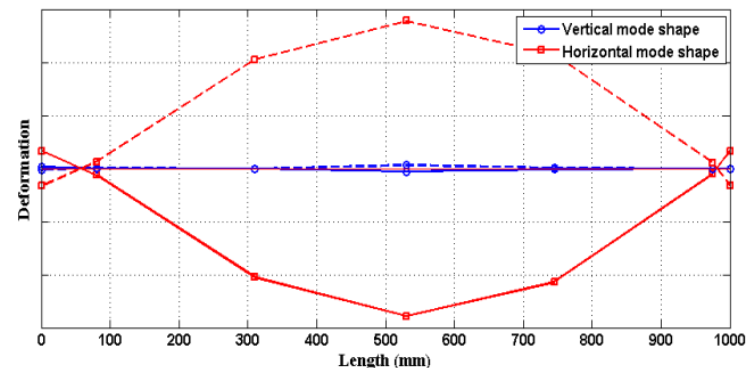

(b)

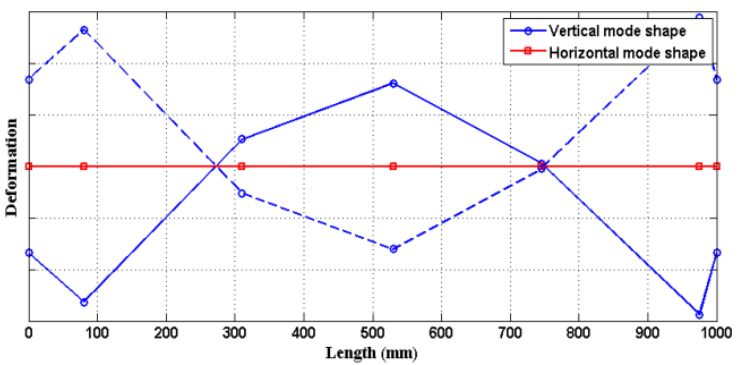

(d)

Figure 2. Mode shapes of the test rig: (a) first mode; (b) second mode; (c) third mode and (d) fourth mode.

Table 2. Mass unbalances and phase angles of 13 runs.

\begin{tabular}{|c|c|c|c|c|}
\hline \multirow[t]{2}{*}{ Run No. } & \multicolumn{4}{|c|}{ Added Unbalance $\left(\mathrm{gcm} @ \theta^{\circ}\right)$} \\
\hline & \multicolumn{2}{|l|}{ Disc D1 } & \multicolumn{2}{|l|}{ Disc D2 } \\
\hline run0 & Residual unbalance & $e_{1,0}$ & Residual unbalance & $e_{2,0}$ \\
\hline run 1 & $3 \mathrm{~g} \times 6 \mathrm{~cm} @ 30^{\circ}=18 \mathrm{gcm} @ 30^{\circ}$ & $e_{1,0}+e_{1,1}$ & Residual unbalance & $e_{2,0}$ \\
\hline run2 & Residual unbalance & $e_{1,0}$ & $3 \mathrm{~g} \times 6 \mathrm{~cm} @ 30^{\circ}=18 \mathrm{gcm} @ 30^{\circ}$ & $e_{2,0}+e_{2,2}$ \\
\hline run3 & $7 \mathrm{~g} \times 6 \mathrm{~cm} @ 60^{\circ}=42 \mathrm{gcm} @ 60^{\circ}$ & $e_{1,0}+e_{1,3}$ & $3 \mathrm{~g} \times 6 \mathrm{~cm} @ 150^{\circ}=18 \mathrm{gcm} @ 150^{\circ}$ & $e_{2,0}+e_{2,3}$ \\
\hline run 4 & $5 \mathrm{~g} \times 6 \mathrm{~cm} @ 60^{\circ}=30 \mathrm{gcm} @ 60^{\circ}$ & $e_{1,0}+e_{1,4}$ & $7 \mathrm{~g} \times 6 \mathrm{~cm} @ 150^{\circ}=42 \mathrm{gcm} @ 150^{\circ}$ & $e_{2,0}+e_{2,4}$ \\
\hline run5 & $7 \mathrm{~g} \times 6 \mathrm{~cm} @ 30^{\circ}=42 \mathrm{gcm} @ 30^{\circ}$ & $e_{1,0}+e_{1,5}$ & $3 \mathrm{~g} \times 6 \mathrm{~cm} @ 330^{\circ}=18 \mathrm{gcm} @ 330^{\circ}$ & $e_{2,0}+e_{2,5}$ \\
\hline run6 & $5 \mathrm{~g} \times 6 \mathrm{~cm} @ 180^{\circ}=30 \mathrm{gcm} @ 180^{\circ}$ & $e_{1,0}+e_{1,6}$ & $3 \mathrm{~g} \times 6 \mathrm{~cm} @ 30^{\circ}=18 \mathrm{gcm} @ 30^{\circ}$ & $e_{2,0}+e_{2,6}$ \\
\hline $\operatorname{run} 7$ & $5 \mathrm{~g} \times 6 \mathrm{~cm} @ 330^{\circ}=30 \mathrm{gcm} @ 330^{\circ}$ & $e_{1,0}+e_{1,7}$ & $3 \mathrm{~g} \times 6 \mathrm{~cm} @ 210^{\circ}=18 \mathrm{gcm} @ 210^{\circ}$ & $e_{2,0}+e_{2,7}$ \\
\hline run 8 & $3 \mathrm{~g} \times 6 \mathrm{~cm} @ 90^{\circ}=18 \mathrm{gcm} @ 90^{\circ}$ & $e_{1,0}+e_{1,8}$ & $5 \mathrm{~g} \times 6 \mathrm{~cm} @ 30^{\circ}=30 \mathrm{gcm} @ 30^{\circ}$ & $e_{2,0}+e_{2,8}$ \\
\hline run 9 & $3 \mathrm{~g} \times 6 \mathrm{~cm} @ 30^{\circ}=18 \mathrm{gcm} @ 30^{\circ}$ & $e_{1,0}+e_{1,9}$ & $5 \mathrm{~g} \times 6 \mathrm{~cm} @ 90^{\circ}=30 \mathrm{gcm} @ 90^{\circ}$ & $e_{2,0}+e_{2,9}$ \\
\hline $\operatorname{run} 10$ & $3 \mathrm{~g} \times 6 \mathrm{~cm} @ 120^{\circ}=18 \mathrm{gcm} @ 120^{\circ}$ & $e_{1,0}+e_{1,10}$ & $5 \mathrm{~g} \times 6 \mathrm{~cm} @ 270^{\circ}=30 \mathrm{gcm} @ 270^{\circ}$ & $e_{2,0}+e_{2,10}$ \\
\hline run 11 & $3 \mathrm{~g} \times 6 \mathrm{~cm} @ 90^{\circ}=18 \mathrm{gcm} @ 90^{\circ}$ & $e_{1,0}+e_{1,11}$ & $7 \mathrm{~g} \times 6 \mathrm{~cm} @ 240^{\circ}=42 \mathrm{gcm} @ 240^{\circ}$ & $e_{2,0}+e_{2,11}$ \\
\hline $\operatorname{run} 12$ & $5 \mathrm{~g} \times 6 \mathrm{~cm} @ 90^{\circ}=30 \mathrm{gcm} @ 90^{\circ}$ & $e_{1,0}+e_{1,12}$ & $7 \mathrm{~g} \times 6 \mathrm{~cm} @ 60^{\circ}=42 \mathrm{gcm} @ 60^{\circ}$ & $e_{2,0}+e_{2,12}$ \\
\hline
\end{tabular}




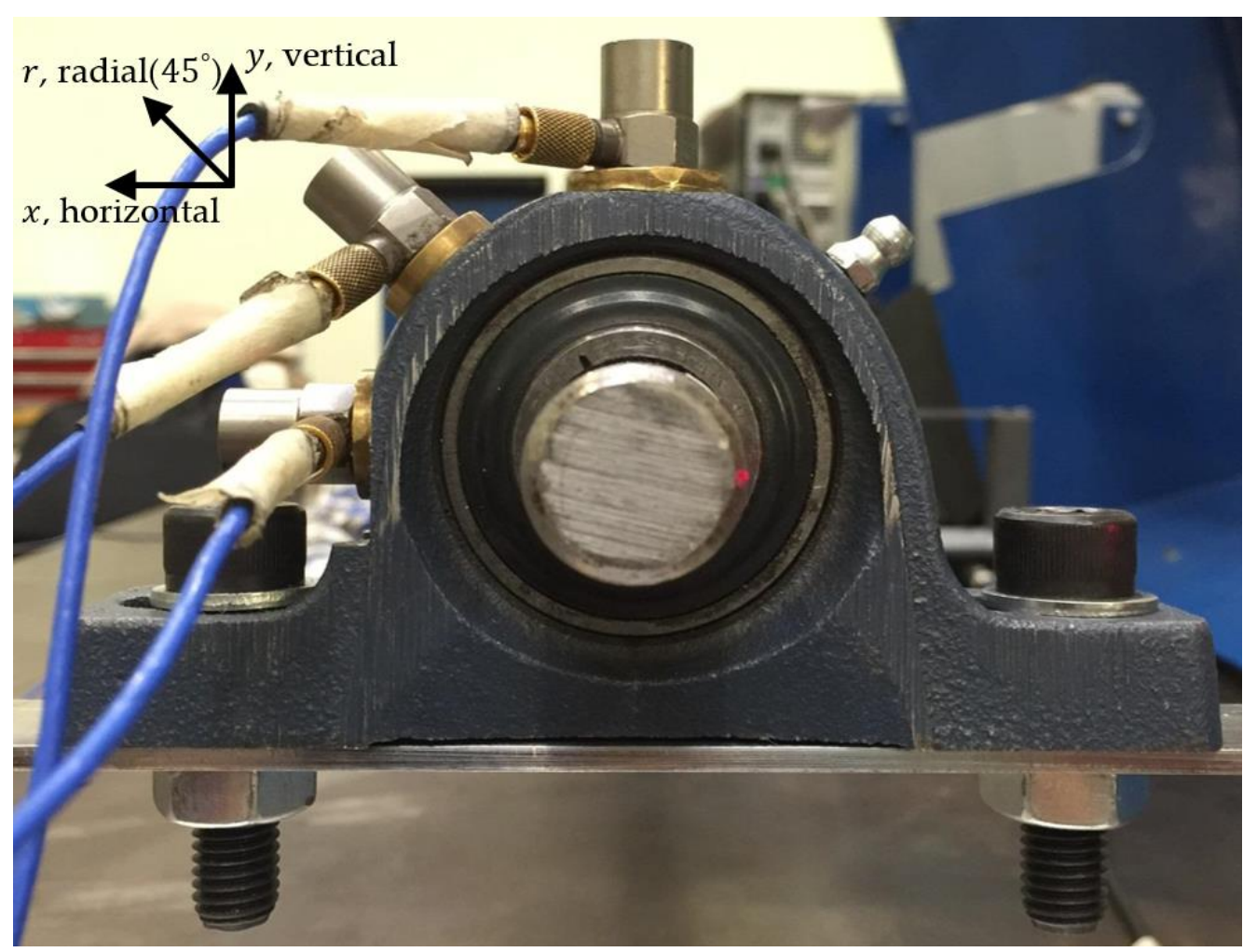

Figure 3. Arrangement of accelerometers on the bearing housing.

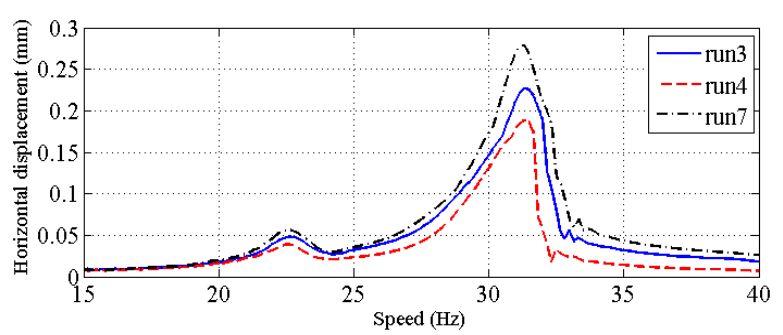

(a)

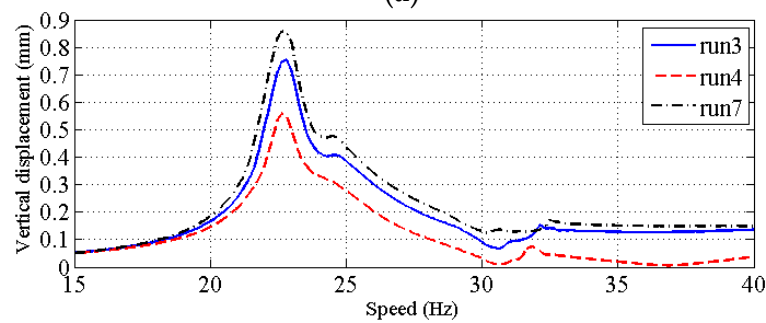

(c)

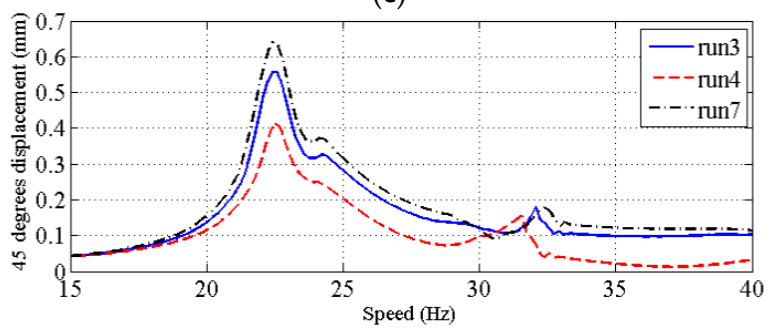

(e)

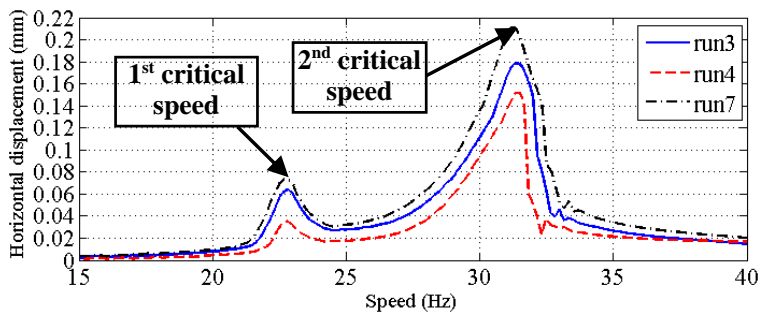

(b)

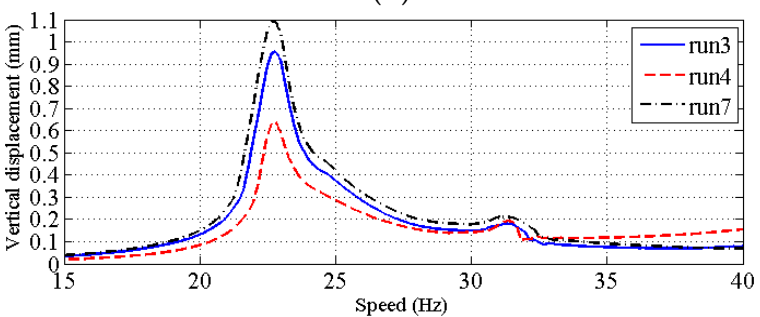

(d)

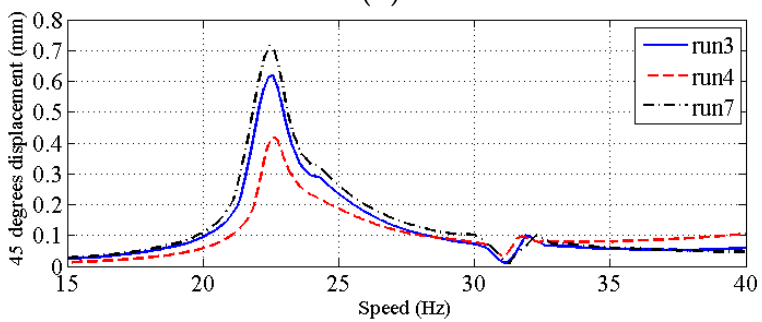

(f)

Figure 4. Typical measured $1 \times$ displacement responses in (a) B1 horizontal; (b) B2 horizontal; (c) B1 vertical; (d) B2 vertical; (e) B1 radial $45^{\circ}$ and (f) B2 radial $45^{\circ}$ for the experimental runs 3, 4 and 7. 


\section{Results and Discussion}

Machine run numbers 0, 1 and 2 were used to construct the sensitivity matrix using Equation (3). First, for each case in Table 2, the unbalances were estimated using the measured vibration response from both vertical and horizontal directions of the whole run-up speed range in a single band. Then, the same unbalance estimation process was repeated using the radial responses measured by the accelerometers mounted at $45^{\circ}$ on the bearing housings. A comparison between the actual added and estimated mass unbalances (both unbalance masses and their phases) on the balance discs D1 and D2 is presented in Tables 3 and 4, respectively. For the sake of easy comparison, the results in Tables 3 and 4 are also presented in the form of a grouped bar chart in Figure 5. It is obvious from Figure 5 as well as Tables 3 and 4 that the estimated unbalances for all cases using vibration measurements at either vertical and horizontal directions or the radial $45^{\circ}$ direction are close to the actual added unbalances.

Therefore, the current industrial application of the IC balancing method can be simplified and enhanced by using a single vibration sensor per bearing pedestal instead of two. This improvement will increase the efficiency of the IC method as it will save the computational efforts and reduce the time consumed during data analysis. In addition, it can be clearly seen that when applying the IC balancing method using the vibration response acquired at the whole run-up speed range in a single band, the certainty of reliably achieving an accurate rotor unbalance (both amplitude and phase) estimation is high.

Table 3. Comparison between the actual and estimated unbalances (disc D1).

\begin{tabular}{|c|c|c|c|c|}
\hline \multirow{2}{*}{ Case No. } & \multirow{2}{*}{\multicolumn{2}{|c|}{ Added Unbalance $\left(\operatorname{gcm} @ \theta^{\circ}\right)$}} & \multicolumn{2}{|c|}{ Estimated Unbalance $\left(\operatorname{gcm} @ \theta^{\circ}\right)$} \\
\hline & & & Vertical and Horizontal & Radial $45^{\circ}$ \\
\hline Case 1 & run $3-\operatorname{run} 0$ & $e_{1,3}=42 @ 60^{\circ}$ & $45.74 @ 62.9^{\circ}$ & $53.9 @ 60.5^{\circ}$ \\
\hline Case 2 & run $4-r u n 0$ & $e_{1,4}=30 @ 60^{\circ}$ & $27.52 @ 55.4^{\circ}$ & $31.36 @ 62.76^{\circ}$ \\
\hline Case 3 & run $5-r u n 0$ & $e_{1,5}=42 @ 30^{\circ}$ & $54 @ 37.16^{\circ}$ & $52.54 @ 36.05^{\circ}$ \\
\hline Case 4 & run6 - run 0 & $e_{1,6}=30 @ 180^{\circ}$ & $33.07 @ 185.2^{\circ}$ & $39.97 @ 179.5^{\circ}$ \\
\hline Case 5 & $\operatorname{run} 7-\operatorname{run} 0$ & $e_{1,7}=30 @ 330^{\circ}$ & $35.49 @ 332.4^{\circ}$ & $39.08 @ 326.2^{\circ}$ \\
\hline Case 6 & run $8-r u n 0$ & $e_{1,8}=18 @ 90^{\circ}$ & $21.63 @ 112.1^{\circ}$ & $16.62 @ 100.5^{\circ}$ \\
\hline Case 7 & $\operatorname{run} 9-\operatorname{run} 0$ & $e_{1,9}=18 @ 30^{\circ}$ & $15.59 @ 23.45^{\circ}$ & $18.14 @ 23.64^{\circ}$ \\
\hline Case 8 & $\operatorname{run} 10-\operatorname{run} 0$ & $e_{1,10}=18 @ 120^{\circ}$ & $17.1 @ 120.5^{\circ}$ & $20.9 @ 123.3^{\circ}$ \\
\hline Case 9 & run $11-r u n 0$ & $e_{111}=18 @ 90^{\circ}$ & $18.24 @ 88.27^{\circ}$ & $20.42 @ 90.95^{\circ}$ \\
\hline Case 10 & $\operatorname{run} 12-\operatorname{run} 0$ & $e_{1,12}=30 @ 90^{\circ}$ & $31.11 @ 100.7^{\circ}$ & $37.18 @ 95.94^{\circ}$ \\
\hline
\end{tabular}

Table 4. Comparison between the actual and estimated unbalances (disc D2).

\begin{tabular}{|c|c|c|c|c|}
\hline \multirow{2}{*}{ Case No. } & \multirow{2}{*}{\multicolumn{2}{|c|}{ Added Unbalance $\left(\operatorname{gcm} @ \theta^{\circ}\right)$}} & \multicolumn{2}{|c|}{ Estimated Unbalance $\left(\right.$ gcm $\left.@ \theta^{\circ}\right)$} \\
\hline & & & Vertical and Horizontal & Radial $45^{\circ}$ \\
\hline Case 1 & run $3-\operatorname{run} 0$ & $e_{2,3}=18 @ 150^{\circ}$ & $26.07 @ 160.9^{\circ}$ & $19.25 @ 159.8^{\circ}$ \\
\hline Case 2 & run $4-\operatorname{run} 0$ & $e_{2,4}=42 @ 150^{\circ}$ & $47.43 @ 158.7^{\circ}$ & $56.8 @ 152.5^{\circ}$ \\
\hline Case 3 & run5 - run0 & $e_{2,5}=18 @ 330^{\circ}$ & $17.41 @ 322.3^{\circ}$ & $18.95 @ 322^{\circ}$ \\
\hline Case 4 & run6 - run 0 & $e_{2,6}=18 @ 30^{\circ}$ & $15.88 @ 18.46^{\circ}$ & $17.91 @ 25.97^{\circ}$ \\
\hline Case 5 & $\operatorname{run} 7-\operatorname{run} 0$ & $e_{2,7}=18 @ 210^{\circ}$ & $15.16 @ 185^{\circ}$ & $14.21 @ 208.3^{\circ}$ \\
\hline Case 6 & run $8-\operatorname{run} 0$ & $e_{2,8}=30 @ 30^{\circ}$ & $32.38 @ 32.79^{\circ}$ & $38.06 @ 28.86^{\circ}$ \\
\hline Case 7 & $\operatorname{run} 9-\operatorname{run} 0$ & $e_{2,9}=30 @ 90^{\circ}$ & $37.49 @ 102.4^{\circ}$ & $34.56 @ 99.34^{\circ}$ \\
\hline Case 8 & $\operatorname{run} 10-\operatorname{run} 0$ & $e_{210}=30 @ 270^{\circ}$ & $37.31 @ 273.1^{\circ}$ & $35.57 @ 283.4^{\circ}$ \\
\hline Case 9 & run $11-\operatorname{run} 0$ & $e_{2,11}=42 @ 240^{\circ}$ & $52.45 @ 244.9^{\circ}$ & $49.22 @ 252.3^{\circ}$ \\
\hline Case 10 & $\operatorname{run} 12-\operatorname{run} 0$ & $e_{2,12}=42 @ 60^{\circ}$ & $42.51 @ 67.14^{\circ}$ & $45.02 @ 65.05^{\circ}$ \\
\hline
\end{tabular}




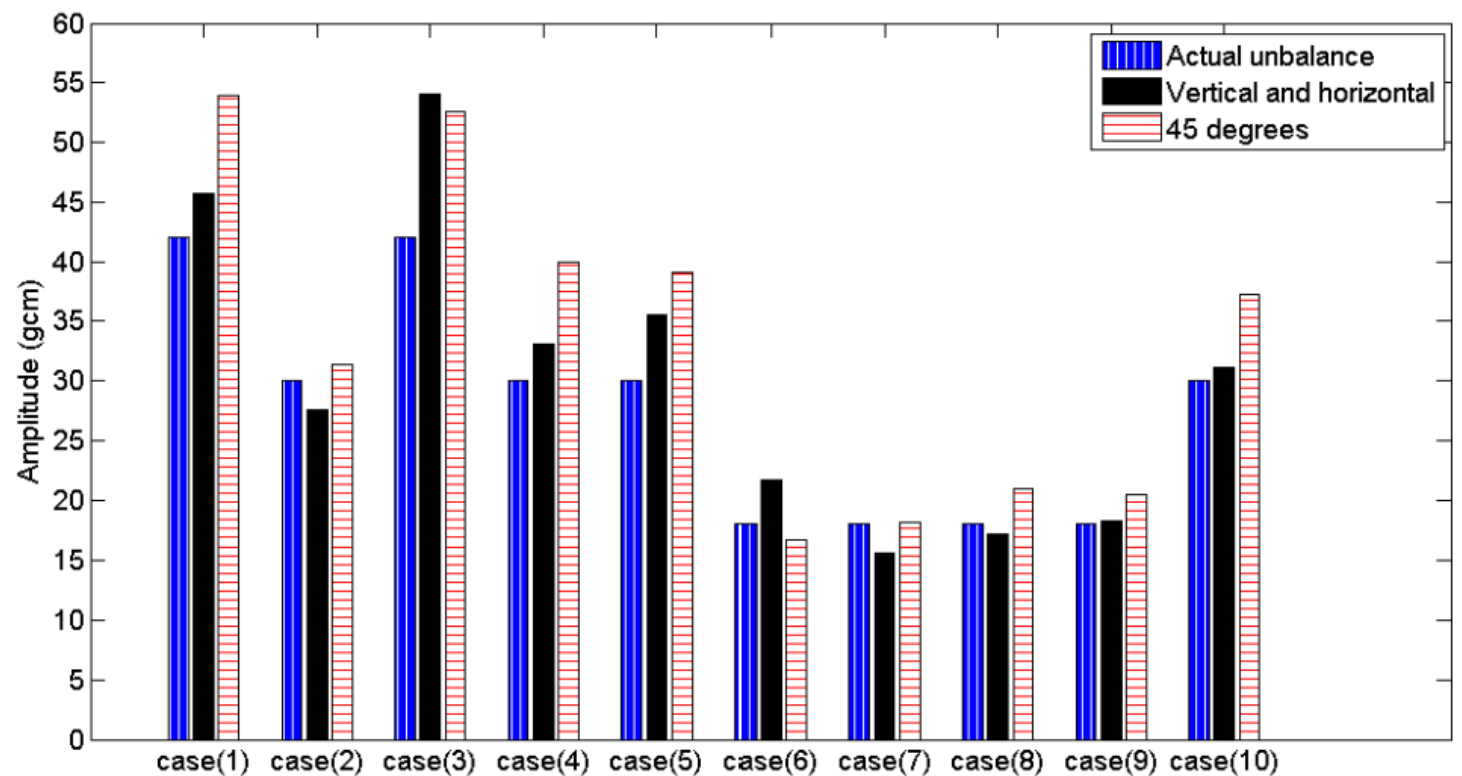

(a)

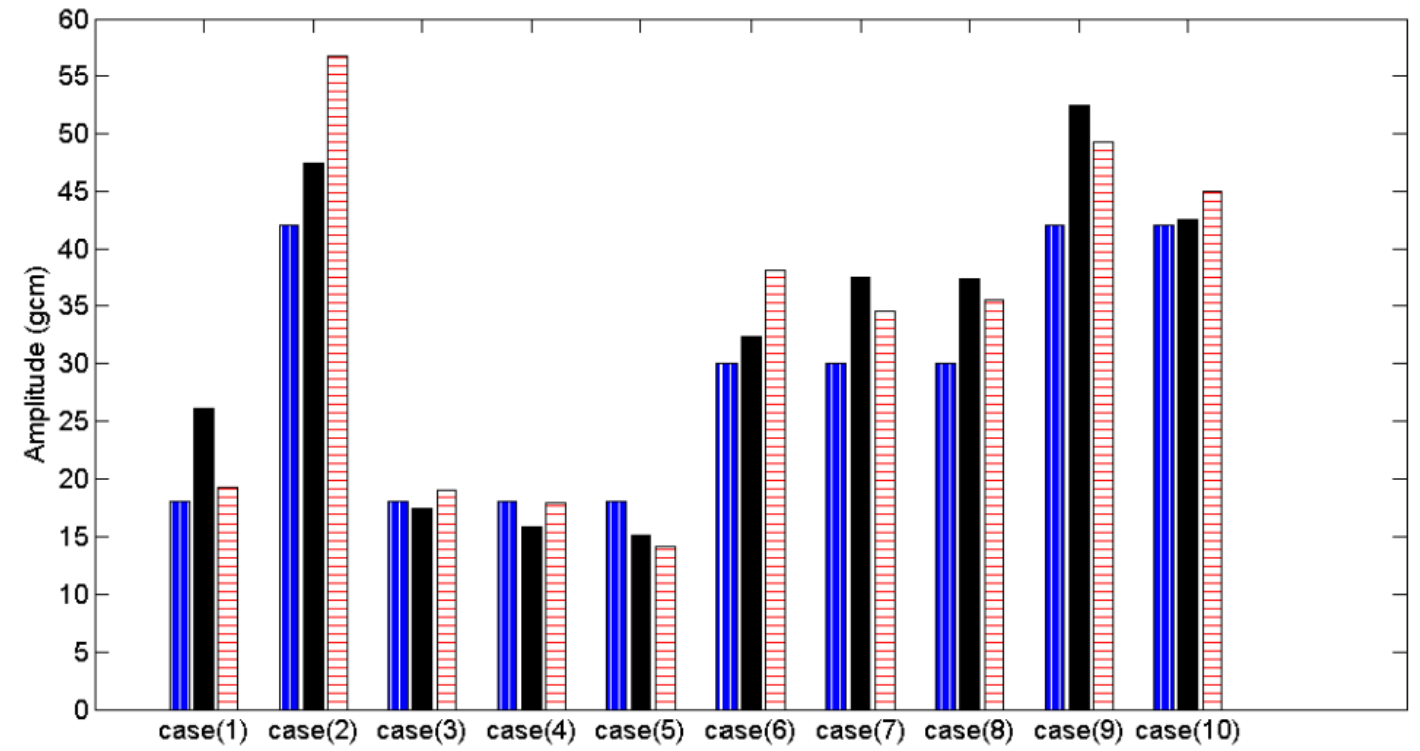

(b)

Figure 5. Grouped bar chart of the comparison between actual and estimated unbalances for (a) disc D1 and (b) disc D2.

\section{Conclusions}

This paper compared the application of the IC balancing approach using vibration measurements acquired at two directions (vertical and horizontal) with one radial direction. In the case of vibration measurements from one radial direction, the accelerometer is mounted at $45^{\circ}$ to both the vertical and horizontal directions on each bearing housing/pedestal in the machine in order to include the vibration effect from both the vertical and horizontal directions. Vibration responses from 13 run-ups of a small test rig are used in the unbalance estimation. The results showed that the application of the IC balancing approach using measured vibration responses from a single vibration sensor $\left(45^{\circ}\right.$ direction) per bearing pedestal provides as good estimation of the rotor unbalance (both amplitude and phase) as when two vibration sensors (vertical and horizontal directions) per bearing pedestal are used. Therefore, the use of one vibration sensor in a radial direction per bearing pedestal is a viable 
option for rotor unbalance estimation based on the present experimental study. This way the number of vibration sensors per bearing pedestal can be reduced to half. This practice is definitely welcomed by any industry as it will significantly reduce the time needed for the complex signal processing required for rotor unbalance estimation. In addition, the reduction of the number of sensors by half will definitely save the cost of the vibration instrumentation and their maintenance.

Acknowledgments: The first author gratefully thanks the government of the Kingdom of Saudi Arabia for granting him a full scholarship under the King Abdullah Scholarship Program.

Author Contributions: Sami Ibn Shamsah and Jyoti Sinha conceived and designed the experiments; Sami Ibn Shamsah performed the experiments and initial analyses; and remaining work together.

Conflicts of Interest: The authors declare no conflict of interest.

\section{References}

1. Yunusa-Kaltungo, A.; Sinha, J.K.; Elbhbah, K. An improved data fusion technique for faults diagnosis in rotating machines. Measurement 2014, 58, 27-32. [CrossRef]

2. Nembhard, A.; Sinha, J.K.; Pinkerton, A.; Elbhbah, K. Combined vibration and thermal analysis for the condition monitoring of rotating machinery. Struct. Health Monit. 2014, 13, 281-295. [CrossRef]

3. Sinha, J.K. Vibration Analysis, Instruments, and Signal Processing; CRC Press: Boca Raton, FL, USA, 2014; pp. 264-275.

4. Darlow, M.S. Balancing of high-speed machinery: Theory, methods and experimental results. Mech. Syst. Sig. Process. 1987, 1, 105-134. [CrossRef]

5. Li, G.; Lin, Z.; Allaire, P.E. Robust Optimal Balancing of High-Speed Machinery Using Convex Optimization. J. Vib. Acoust. 2008, 130, 031008. [CrossRef]

6. Santos, F.L.; Duarte, M.L.M.; de Faria, M.T.C.; Eduardo, A.C. Balancing of a rigid rotor using Artificial Neural Network to predict the correction masses. Acta Scientiarum Technol. 2009, 31, 151-157. [CrossRef]

7. Deepthikumar, M.B.; Sekhar, A.S.; Srikanthan, M.R. Modal balancing of flexible rotors with bow and distributed unbalance. J. Sound Vib. 2013, 332, 6216-6233. [CrossRef]

8. Khulief, Y.A.; Mohiuddin, M.A.; El-Gebeily, M. A New Method for Field-Balancing of High-Speed Flexible Rotors without Trial Weights. Int. J. Rotating Mach. 2014, 2014, 603241. [CrossRef]

9. Lees, A.W.; Sinha, J.K.; Friswell, M.I. Model-based identification of rotating machines. Mech. Syst. Sig. Process. 2009, 23, 1884-1893. [CrossRef]

10. Nembhard, A.D.; Sinha, J.K. Comparison of experimental observations in rotating machines with simple mathematical simulations. Measurement 2016, 89, 120-136. [CrossRef]

11. Thearle, E. Dynamic balancing of rotating machinery in the field. Trans. ASME 1934, 56, 745-753.

12. Hopkirk, K. Notes on methods of balancing. The Eng. 1940, 170, 38-39.

13. Zhou, S.; Dyer, S.W.; Shin, K.; Shi, J.; Ni, J. Extended influence coefficient method for rotor active balancing during acceleration. J. Dyn. Syst. Meas. Contr. 2004, 126, 219-223. [CrossRef]

14. Ibn Shamsah, S.; Sinha, J.K.; Mandal, P. Precaution during the field balancing of rotating machines. In Proceedings of the 1st International Conference on Maintenance Engineering, Manchester, UK, 30-31 August 2016.

15. Ibn Shamsah, S.; Sinha, J.K.; Mandal, P. Sensitivity analysis of in-situ rotor balancing. In Proceedings of the Vibration in Rotating Machinery (VIRM 11), Manchester, UK, 13-15 September 2016.

16. Bishop, R.E.; Gladwell, G.M. The vibration and balancing of an unbalanced flexible rotor. J. Mech. Eng. Sci. 1959, 1, 66-77. [CrossRef]

17. Darlow, M.S. Balancing of High-Speed Machinery; Springer: New York, NY, USA, 1989.

18. Fang, J.; Wang, Y.; Han, B.; Zheng, S. Field balancing of magnetically levitated rotors without trial weights. Sensors 2013, 13, 16000-16022. [CrossRef]

19. Zhou, S.; Shi, J. Active balancing and vibration control of rotating machinery: A survey. Shock Vibr. Digest 2001, 33, 361-371. [CrossRef]

20. Dyer, S.W.; Ni, J. Adaptive influence coefficient control of single-plane active balancing systems for rotating machinery. J. Manuf. Sci. Eng. 2000, 123, 291-298. [CrossRef]

21. Parkinson, A.G. Balancing of rotating machinery. J. Mech. Eng. Sci. 1991, 205, 53-66. [CrossRef] 
22. Goodman, T.P. A least-squares method for computing balance corrections. J. Manuf. Sci. Eng. 1964, 86, 273-277. [CrossRef]

23. Lund, J.W.; Tonnesen, J. Analysis and experiments on multi-plane balancing of a flexible rotor. J. Manuf. Sci. Eng. 1972, 94, 233-242. [CrossRef]

24. Tessarzik, J.M.; Badgley, R.H.; Anderson, W.J. Flexible rotor balancing by the exact point-speed influence coefficient method. J. Manuf. Sci. Eng. 1972, 94, 148-158. [CrossRef]

25. Grobel, L. Balancing turbine-generator rotors. Gen. Electr. Rev. 1953, 56, 22.

26. Yu, X. General influence coefficient algorithm in balancing of rotating machinery. Int. J. Rotating Mach. 2004, 10, 85-90. [CrossRef]

27. Sinha, J.K.; Lees, A.W.; Friswell, M.I. Estimating unbalance and misalignment of a flexible rotating machine from a single run-down. J. Sound Vib. 2004, 272, 967-989. [CrossRef]

28. Sinha, J.K.; Friswell, M.I.; Lees, A.W. The identification of the unbalance and the foundation model of a flexible rotating machine from a single run-down. Mech. Syst. Sig. Process. 2002, 16, 255-271. [CrossRef]

29. Lee, S.-H.; Kim, B.-S.; Moon, J.-D.; Kim, D.-H. A study on active balancing for rotating machinery using influence coefficient method. In Proceedings of the 2005 International Symposium on Computational Intelligence in Robotics and Automation, Espoo, Finland, 27-30 June 2005; pp. 659-664.

(c) 2016 by the authors; licensee MDPI, Basel, Switzerland. This article is an open access article distributed under the terms and conditions of the Creative Commons Attribution (CC-BY) license (http://creativecommons.org/licenses/by/4.0/). 